\title{
Severe hypocalcemia mimicking ST-segment elevation acute myocardial infarction
}

\author{
Piotr Kukla M.D., Ph.D. ${ }^{1}$ | Monika Kulik M.D. ${ }^{2}$ | Marek Jastrzębski M.D., Ph.D. ${ }^{3}$ | \\ Leszek Bryniarski M.D., Ph.D. ${ }^{3}$ | Danuta Czarnecka M.D., Ph.D. ${ }^{3}$ | Adrian Baranchuk \\ M.D., Ph.D. ${ }^{4}$
}

${ }^{1}$ Department of Cardiology and Internal Diseases, Specialistic Hospital, Gorlice, Poland

${ }^{2}$ Department of Internal Medicine and Toxicology, Specialistic Hospital St Lucas, Tarnów, Poland

${ }^{3}$ Jagiellonian University Medical College, First Department of Cardiology, Interventional Electrocardiology and Hypertension, Kraków, Poland

${ }^{4}$ Division of Cardiology, Kingston General Hospital, Queen's University, Kingston, ON, Canada

\section{Correspondence}

Piotr Kukla, Department of Cardiology and Internal Diseases, Specialistic Hospital,

Gorlice, Poland.

Email: kukla_piotr@poczta.onet.pl
Hypocalcemia is mainly the consequence of hypoalbuminemia, advanced renal impairment, cirrhosis, malnutrition, or sepsis. The most common ECG manifestation of hypocalcemia is QT prolongation as a result of ST segment lengthening. Very occasionally, hypocalcemia can manifest with ST segment elevation forcing the differential diagnosis with ST elevation MI. We described a case of severe hypocalcemia manifesting in electrocardiogram with a J point elevation, absent of ST segment and with associated short QT interval mimicking acute myocardial infarction.

KEYWORDS

electrocardiogram, hypercalcemia, QT interval
Hypocalcemia is mainly the consequence of hypoalbuminemia, advanced renal impairment, cirrhosis, malnutrition, or sepsis. The most common ECG manifestation of hypocalcemia is QT prolongation as a result of ST segment lengthening (Chorin, Rosso, \& Viskin, 2016). Very occasionally, hypocalcemia can manifest with ST-segment elevation forcing the differential diagnosis with ST elevation MI (STEMI) (Khardori et al., 1985; Reddy, Gould, \& Gomprecht, 1974). We described a case of severe hypocalcemia manifesting in electrocardiogram with a J point elevation, absent of ST segment and with associated short QT interval mimicking acute myocardial infarction.

\section{1 | CASE PRESENTATION}

A 50-year-old male, with no medical history and not taking any medications presented to the emergency room after he mistakenly drank $50 \mathrm{ml}$ of fluid containing hydrofluoric acid (HFA A 5) in his car repair shop. Shortly after the ingestion, he complained of chest pain and shortness of breath. He arrived to the emergency room 2 hours later. He was alert and conscious, but intermittently restless and agitated.
Surface 12-lead ECG on admission depicted sinus rhythm at 115120 bpm. P-wave abnormalities ( $P$ "mitrale"- bifid $P$ wave in inferior leads II, III, aVF and leads $\mathrm{V}_{2}-\mathrm{V}_{6}$ ), PQ interval $160 \mathrm{~ms}$, QRS duration of $90 \mathrm{~ms}$, QT interval of $240 \mathrm{~ms}$ (limb leads), $280 \mathrm{~ms}$ (precordial leads), $\mathrm{QT}_{\text {apex }}-160$ to $180 \mathrm{~ms}$, corrected $\mathrm{QT}_{\text {apex }}-221 \mathrm{~ms}$. The shortest QTc interval (limb leads) $-320 \mathrm{~ms}$. The J point elevation in lateral leads (I and $\mathrm{aVL}$ ) with mirror J point depression in leads (II, III, and aVF), absent ST segment and tall peaked T waves (Fig. 1).

\section{2 | CLINICAL COURSE}

In the emergency room his clinical status quickly deteriorated. Anxiety and agitation intensified, and speech became confusing. Swelling and face redness rapidly developed. Burns in mouth mucosa were observed. The patient complained of chest pain. His heart rate was regular at $140 \mathrm{bpm}, \mathrm{BP}$ was 115/75 mmHg, no evidence of heart failure.

Initial and subsequent blood gas parameters can be seen in Table 1 Potassium: $3.5 \mathrm{mmol} / \mathrm{L}$, sodium: $142 \mathrm{mmol} / \mathrm{L}$. Very low calcium concentration paid special attention: ionized calcium: $0.8 \mathrm{mmol} / \mathrm{L}$. Other 


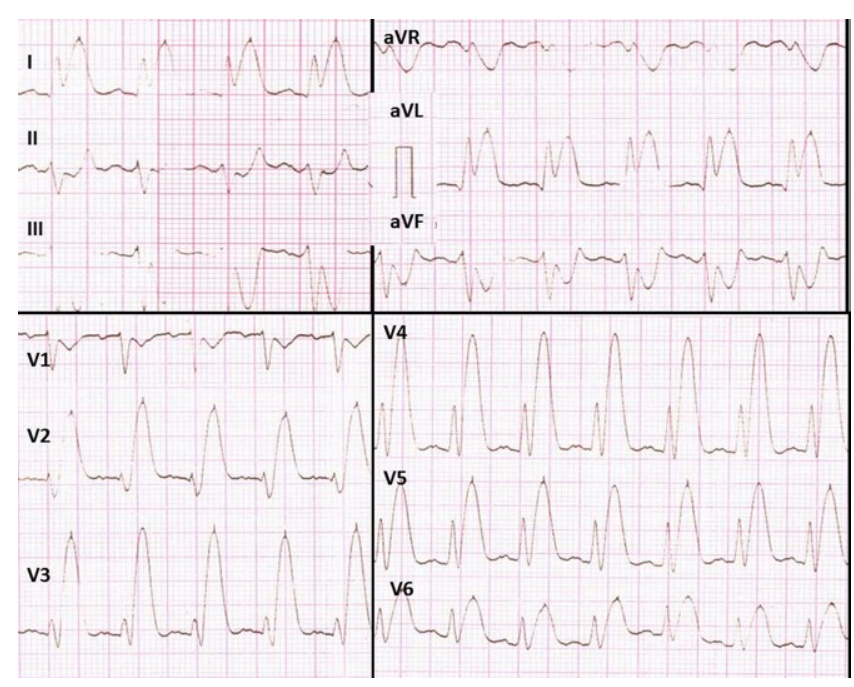

FIGURE 1 Electrocardiogram on hospital admission. Surface 12-lead ECG on admission depicted sinus rhythm at 115-120 bpm. P-wave abnormalities ( $\mathrm{P}$ "mitrale"- bifid P wave in inferior leads II, III, aVF and leads $V_{2}-V_{6}$ ), PQ interval $160 \mathrm{~ms}$, QRS duration of $90 \mathrm{~ms}$, QT interval of $240 \mathrm{~ms}$ (limb leads), QTc interval - $320 \mathrm{~ms}$, QT interval 280 ms (precordial leads), QT apex - 160-180 ms, corrected QT apex - 221 ms. J point elevation in lateral leads ( $\mathrm{and} \mathrm{aVL}$ ) with mirror J point depression in leads (II, III and aVF), absent ST segment and tall peaked $\mathrm{T}$ waves

TABLE 1 Initial and control blood gas parameters

\begin{tabular}{lcc} 
Gas blood parameters & On admission & Control \\
$\mathrm{pH}$ & 7.24 & 7.1 \\
$\mathrm{pCO}_{2}(\mathrm{mmHg})$ & 32 & 30 \\
$\mathrm{pO}_{2}(\mathrm{mmHg})$ & 124 & 125 \\
$\mathrm{HCO}_{3}(\mathrm{mmol} / \mathrm{l})$ & 13.7 & 10.9 \\
$\mathrm{BE}(\mathrm{mmol} / \mathrm{l})$ & -12.2 & -16.0 \\
\hline
\end{tabular}

biochemical parameters: ASPAT: $85 \mathrm{U} / \mathrm{L}$, ALAT: $37 \mathrm{U} / \mathrm{L}$, INR: 1.2, APTT: $36.1 \mathrm{~s}$, blood platelet: $111000 / \mu l$. Renal function: slightly increased creatinine: $117 \mu \mathrm{mol} / \mathrm{L}$, eGFR: $61 \mathrm{ml} / \mathrm{min}$. Troponin I was in a normal range: $0.1 \mu \mathrm{mol} / \mathrm{L}$. Control total calcium: $0.9 \mathrm{mmol} / \mathrm{L}$ and ionized calcium: $0.3 \mathrm{mmol} / \mathrm{L}$ were much lower than on admission.

Fluid resuscitation was administered. Low molecular heparin and calcium gluconicum were also given. Thirty minutes later, the patient arrested. Resuscitation efforts were initiated including CPR, drugs, and ventilation. The patients died despite all these efforts.

\section{3 | DISCUSSION}

Hypocalcemia is mainly the consequence of hypoalbuminemia, advanced renal impairment, cirrhosis, malnutrition, or sepsis. This case shows an unusual ECG pattern caused by severe hypocalcemia provoked by intoxication with HFA. The most common ECG manifestation of hypocalcemia is QT prolongation as a result of ST segment lengthening (Chorin et al., 2016). If the QTc exceeds >140\% of the upper normal range of the QTc, it usually suggests the $U$ wave presence that represents additional hypokalemia and cardiac repolarization will reveal a QT + U interval (Surawicz, 1974). The duration of ST segment is inversely related to the plasma calcium concentration (Surawicz, 1967). The ST segment lengthening is the better predictor of the plasma calcium concentration than QTc that can be variable (Yu, 1952). In the presence of hypocalcemia the polarity of T wave may remain unchanged but sometimes becomes low, flat, or sharply inverted in leads with an upright QRS complex.

In the presented case, severe hypocalcemia has provoked QTC shortening what is the opposite electrocardiographic change usually seen in this condition. The shortest QTc interval in limb leads is $320 \mathrm{~ms}$ with QT ${ }_{\text {apex }}$ interval of 160-180 ms. The shortened QTc/QT apex associated with absent of ST segment are typical but for hypercalcemia. Nierenberg and Ransil found that the $\mathrm{QT}_{\text {apex }}$ interval correlated better than QTc interval with serum calcium levels. The corrected QT interval $\leq 270 \mathrm{~ms}$ was associated with hypercalcemia in more than $90 \%$ patients (Nierenberg \& Ransil, 1979). In our case of advanced hypocalcemia the corrected $\mathrm{QT}_{\text {apex }}$ is $221 \mathrm{~ms}$.

The presented case showed in ECG the diffuse J point elevation in the lateral leads ( $\mathrm{and} \mathrm{aVL}$ ) along with "mirror" J point depression in the inferior leads (II, III, and aVF). Special attention should be paid to the fact that there is "no ST-segment elevation" but rather "J point elevation." Such an ECG pattern could be easily mistaken as an early stage of STEMI. In turn, in advanced hypocalcemia the coronary artery spasm could be provoked (Popow, Kochanowski, \& Krakowian, 2015). We did not perform the coronary angiography because of the lack of clinical indications. We speculate that the coronary artery spasm could be the one explanation of J point elevation and shortening of QTc. Reddy et al. (1974) and Khardori et al. (1985) described patients with an acute antero-septal injury pattern with no proven subsequent infarction, which they associated with hypocalcemia. In both examples, the patients had complicated coexisting medical problems with associated electrolyte imbalance.

What is the link between HFA and ECG abnormalities in the presented case? HFA is used for cleaning car wheels. HFA has a strong caustic effect due to the formation of fluoride ions, which cause liquefaction necrosis. HFA is absorbed causing the precipitation of water-insoluble calcium fluoride which may result in metabolic disorders, particularly hypokalemia, hypocalcemia, and hypomagnesemia (Dalamaga, Karmaniolas, Nikolaidou, \& Papadavid, 2008;Greco, Hartford, Haith, \& Patton, 1988).

As a conclusion, severe hypocalcemia can mimic acute myocardial infarction with J point elevation, absent of ST segment and shortening of QTc interval.

\section{REFERENCES}

Chorin, E., Rosso, R., \& Viskin, S. (2016). Electrocardiographic manifestation of calcium abnormalities. Annals of Noninvasive Electrocardiology, 21(1), 7-9.

Dalamaga, M., Karmaniolas, K., Nikolaidou, A., \& Papadavid, E. (2008). Hypocalcemia, hypomagnesemia, and hypokalemia following hydrofluoric acid chemical injury. Journal of Burn Care \& Research, 29, 541-543. 
Greco, R. J., Hartford, C. E., Haith Jr, L. R., \& Patton, M. L. (1988). Hydrofluoric acid-induced hypocalcemia. Journal of Trauma, 28, 1593-1596.

Khardori, R., Cohen, B., Taylor, D., Soler, N.G. (1985). Electrocardiographic findings simulating acute myocardial infarction in a compound metabolic aberration. American Journal of Medicine, 78(3), 529-532.

Nierenberg, D. W., \& Ransil, B. J. (1979). Q-aTc interval as a clinical indicator of hypercalcemia. American Journal of Cardiology, 44(2), 243-248.

Popow, M., Kochanowski, J., \& Krakowian, M. (2015). Coronary spasm secondary to hypocalcemia and hypomagnesemia. Kardiologia Polska, 73(1), 57.

Reddy, C., Gould, L., \& Gomprecht, R. (1974). Unusual electrocardiographic manifestations of hypocalcemia. Angiology, 25, 764-768.

Surawicz, B. (1967). Relation between electrocardiogram and electrolytes. American Heart Journal, 73, 814-834.
Surawicz, B. (1974). Electrolytes and the electrocardiogram. Postgraduate Medicine, 55, 123-129.

Yu, P. N. G. (1952). Electrocardiographic changes associated with hypocalcemia and hypercalcemia. American Journal of the Medical Sciences, 224, 413-423.

How to cite this article: Kukla P, Kulik M, Jastrzębski M, Bryniarski L, Czarnecka D, Baranchuk A. Severe hypocalcemia mimicking ST-segment elevation acute myocardial infarction. Ann Noninvasive Electrocardiol. 2017;22:e12401. https://doi.org/10.1111/anec.12401 